\section{End-of-Life Decision Making}

To the Editor:-Eight years ago I completed fieldwork on an ethnography of the decision-making process among patients, families, and physicians regarding cardiopulmonary resuscitation. ${ }^{1}$ Since then, while working as a community practitioner, I have tried to keep up with the research on this issue and recently read three pertinent articles in JGIM. ${ }^{2-4}$ These stimulated me to share the following two thoughts.

First, I am pleased that the results of the anthropologic investigations others and I conducted have been confirmed by quantitatively based studies. ${ }^{2}$ Our small ethnographies predicted that decisions about clinical care at the end of life can be understood only in the context of patients' and their families' world views, and that an ongoing physician-patient-family relationship is the preeminent "tool" to address effectively these sensitive concerns. ${ }^{1,5,6}$ They also anticipated Aronowitz' and Asch's comments that positivist research and interventional trials may not help us understand or refine this decision-making process, given the perplexing sociocultural influences on which it is dependent. ${ }^{3}$

Second, I am troubled that many authors seemingly continue to expect that normative guidelines alone will improve endof-life care. I believe guidelines can be used only as prompts for triggering meaningful discourse and reflection, in which physicians must rely on their abilities to be at once flexible, compassionate, and realistic. Rather than focusing on deterministic blueprints, researchers, teachers, students, and practitioners might try observing communicative physicians who are adept at building tangible plans out of the complex medical and human factors that affect do-not-resuscitate decisions. They also would be well served by spending more time developing the acuity of their greatest medical resources: their ears, their eyes, and their intuitions.

It is time we accept the limitations of the traditional methodologies used to study resuscitative decision making, transcend the tendency toward offering physicians prescriptive advice for managing death, and look rather to clinicians skilled in effectively addressing resuscitative issues as exemplars worthy of emulating.-William B. Ventres, MD, MA, Providence Family MedicineSoutheast, Portland, Ore.

JGIM welcomes your letters and comments. Letters may contain brief commentaries on articles published in the Journal, illustrative case reports, general suggestions for improving the Journal, or other information of interest to readers. Letters to the Editor should not exceed 450 words in length and should be sent in triplicate (typed, double-spaced). We cannot guarantee publication and we may edit to improve readability.

You may send your letters to us by mail, fax, or e-mail: JGIM, Veterans Affairs Medical Center (JGIM-111), University and Woodland Avenues, Philadelphia, PA 19104; fax: 215-8234450; e-mail:jgim@mail.med.upenn.edu.

\section{REFERENCES}

1. Ventres WB, Nichter M, Reed R, Frankel RM. Limitation of medical care and ethnographic analysis. J Clin Ethics. 1993;4:134-45.

2. Teno JM, Stevens M, Spernak S, Lynn J. Role of written advance directives in decision making: insights from qualitative and quantitative data. J Gen Intern Med. 1998;13:439-46.

3. Fischer GS, Tulsky JA, Rose MR, Siminoff LA, Arnold RM. Patient knowledge and physician predictions of treatment preferences after discussion of advance directives. J Gen Intern Med. 1998;13:447-54.

4. Aronowitz RA, Asch DA. Cursing the darkness: are there limits to end-of-life research? J Gen Intern Med. 1998;13:495-6.

5. Miller DK, Coe RM, Hyers TM. Achieving consensus on withdrawing or withholding care for critically ill patients. J Gen Intern Med. 1992;7:475-80.

6. Tulsky JA, Chesney MA, Lo B. How do medical residents discuss resuscitation with patients? J Gen Intern Med. 1995;10:436-42.

In reply:-We agree with Dr. Ventres that we must improve communication about advance care planning. Our study (one of those to which he refers) showed that physicians do not communicate important information during such discussions. ${ }^{1}$ Subsequently, we published qualitative work demonstrating deficiencies in the content of these discussions as well, including poor communication skills, inattention to the patients' values and goals, and failure to discuss any but the most simplified scenarios. ${ }^{2}$

The question is what approach will be most effective in changing clinical practice. Dr. Ventres is correct to suggest that we look to expert clinicians for examples. We have recently completed analyzing 51 discussions about advance directives conducted by 18 national experts in physician-patient communication or medical ethics. ${ }^{3}$ These discussions are qualitatively different from the other discussions we studied, and we can learn much from these superb communicators. However, it is not enough for learners to observe these doctors in action. Teachers must take note of the particular behaviors that these physicians exhibit in order to teach them to students. We suspect that the best way to learn these behaviors is to practice them under supervision with actual patients, encounter trained standardized patients who can provide feedback, or role play in workshops with facilitators who are adept at these conversations.- GARY S. Fischer, MD, Robert M. ARNold, MD, University of Pittsburgh, Pittsburgh, Pa., MARY R. Rose, MA, Duke University, Durham, N.C., James A. Tulsky, MD, Durham VA Medical Center, Duke University, Durham, N.C., and Laura A. Siminoff, PhD, Case Western Reserve University, Cleveland, Ohio.

\section{REFERENCES}

1. Fischer GS, Tulsky JA, Rose MR, Siminoff LA, Arnold RM. Patient knowledge and physician predictions of treatment preferences after discussion of advance directives. J Gen Intern Med. 1998;13:447-54.

2. Tulsky JA, Fischer GS, Rose MR, Arnold RM. Opening the black box: how do physicians communicate about advance directives? Ann Intern Med. 1998;129:441-9.

3. Fischer GS, Arnold RM, Melcher J, Tulsky JA. A comparison of expert and non-expert communication styles when discussing advance directives. J Gen Intern Med. 1998;(13 suppl):92. Abstract. 


\section{Dietary Supplements: An Important Component of Alternative Medicine Curricula}

To the Editor:-We commend the initiative by Milan and colleagues on teaching residents about acupuncture, chiropractic, massage therapy, and homeopathy. ${ }^{1}$ The popularity and respectability of complementary/alternative medicine (CAM) in the United States have grown considerably over the past few years. This trend has already been recognized by the National Institutes of Health, and Wetzel et al. recently reported in JAMA that up to $64 \%$ of American medical schools offer courses or selected topics on the subject. ${ }^{2}$ However, as physicians working in a large geriatric practice, we care for a segment of the population with unique patterns of CAM utilization. In our experience, elderly patients are much more likely to use alternative supplements like vitamins, herbs, and other natural products than to use alternative systems like acupuncture or chiropractic. Given the increasing geriatric population, we believe that a CAM curriculum should involve a component on such supplements.

The quality and quantity of scientific evidence supporting the use of some of these supplements have increased steadily over recent years. For example, the use of St. John's wort for the treatment of depression and related disorders is widespread in certain European countries and has been extensively researched. ${ }^{3}$ The use of garlic in the management of hypercholesterolemia and mild hypertension is being studied both in the United States and abroad, albeit with mixed results. ${ }^{4}$ Ginkgo has been investigated as a therapeutic approach in patients with Alzheimer's disease ${ }^{5}$ and peripheral vascular disease. Although none of these supplements has obtained FDA approval as yet, they are frequently used by patients in our geriatric practice. Part of our role as health care providers is to be aware of the potential efficacy and complications of compounds used by our patients and to be able to provide appropriate counseling. This awareness and training should begin in medical school.-Jose Ness, MD, Cynthia Pan, MD, Department of Geriatrics, Mount Sinai Hospital, New York City, N.Y.

\section{REFERENCES}

1. Milan FB, Landau C, Murphy DR, et al. Teaching residents about complementary and alternative medicine in the United States. J Gen Intern Med. 1998;13:562-7.
2. Wetzel MS, Eisenberg DM, Kaptchuk TK. Courses involving complementary and alternative medicine at US medical schools. JAMA. 1998;280:784-7.

3. Linde K, Ramirez G, Mulrow CD, Pauls A, Weidenhammer W, Melchart D. St. John's wort for depression-an overview and metaanalysis of randomized clinical trials. BMJ. 1996;313:253-8.

4. Silagy C, Neil A. Garlic as a lipid-lowering agent-a meta-analysis. J R Colls Physicians Lond. 1994;28:39-45.

5. Le Bars PL, Katz MM, Berman, N, Itil TM, Freedman AM, for the North American EGB Study Group. A placebo-controlled, double blind, randomized trial of an extract of ginkgo biloba for dementia. JAMA. 1997;278:1327-32.

In reply:-Drs. Ness and Pan are entirely correct that the use of herbal and other "dietary supplements" has increased exponentially in many segments of the population, including the geriatric population. The over-the-counter sale of such supplements is a billion-dollar industry with sales increasing by $25 \%$ annually. They are also correct that the scientific evidence to evaluate the efficacy and safety of herbal supplements is steadily increasing. The recent availability of the translated Komission E Papers from Germany is a valuable addition. Given that botanicals are not patentable, companies lack the opportunity to recoup the costs of investigations necessary for FDA approval ( $\$ 140$ million to $\$ 500$ million). Therefore, those expensive but critically important doubleblind, randomized, controlled trials will most likely be few and far between.

The absence of herbal medicine from our curriculum in complementary/alternative medicine does not reflect a lack of recognition on our part of the importance of this area. Rather, it reflects a lack of access to an experienced and credentialed teacher. Herbal medicine is practiced largely by patients themselves. There is currently not an organized field of practice with standardized education or licensure. There are a few individuals from varying backgrounds with interest and self-acquired expertise. Unfortunately, we have not yet found anyone locally to offer such a course in our curriculum. We agree with Drs. Ness and Pan that the need for clinicians to have at least a general understanding of herbal medicine and knowledge of potential interactions with pharmaceuticals is especially great in the geriatric population. We hope that we will be able to add this to our curriculum in the near future.-Felise B. Milan, MD, Carol Landau, PHD, Division of General Internal Medicine, Rhode Island Hospital, Providence, R.I. 